\title{
Factors Associated with Male Involvement in Family Planning in West Pokot County, Kenya
}

\author{
Dennis Butto ${ }^{1, *}$, Samuel Mburu ${ }^{2}$ \\ ${ }^{1}$ Department of Medical Services, Kirinyaga University College, Kenya \\ ${ }^{2}$ School of Health Sciences, Kirinyaga University College, Kenya
}

Copyright $(\subset 2015$ by authors, all rights reserved. Authors agree that this article remains permanently open access under the terms of the Creative Commons Attribution License 4.0 International License

\begin{abstract}
The Contraceptive Prevalence Rate for West Pokot County is estimated to be at a low of $23 \%$ compared to the national prevalence which stands at $43 \%$. This analytic cross sectional study was aimed at establishing the male factors associated with family planning in West Pokot County, Kenya. A total of 266 married men were involved and household was the unit of analysis. The findings of this study demonstrated that $48 \%$ of the respondents were not involved at all in family planning and only $6 \%$ of men were using a family planning method. The age of respondents, educational level, number of children, and type of marriage, knowledge and ease of access to family planning services were all significantly associated with male involvement. Having no education made a man $89 \%$ less likely to be highly involved in family planning (OD $0.117 ; 95 \% \mathrm{CI}$ : $0.03-0.454)$. The study concludes that the level of male involvement in family planning in the county is still low despite interventions both by the government and other nongovernmental organizations. Therefore, more efforts should be made to improve education standards especially for men and to reorient family planning services to make them more accessible to men.
\end{abstract}

Keywords Family Planning, Male Involvement, Unmet Need, Contraceptive Prevalence Rate

\section{Introduction}

Family planning is getting a child by choice and not by mere chance. It involves a conscious decision on size of the family and the spacing between the children. Every day, 1,600 women and more than 10,000 new-borns die from preventable complications during pregnancy and childbirth. Almost $99 \%$ of these maternal and $90 \%$ of neonatal deaths occur in the developing countries. As the first pillar of safe motherhood and an essential component of primary health care, family planning plays a major role in reducing maternal and new-born morbidity and mortality. Family planning enhances efforts to improve family health. However, traditional beliefs, religious barriers and lack of male involvement have weakened family planning interventions [1].

In the 1990s, many women's health programs began to acknowledge that family planning must be viewed in the broader context of reproductive health. The program of action adopted by the International Conference on Population and Development (ICPD) held in Cairo 1994 noted that special efforts ought to be made to emphasize men's shared responsibility and promote their active involvement in responsible parenthood, sexual and reproductive behavior, including family planning; pre-natal, maternal and child health; prevention of Sexually Transmitted Diseases (STDs); and prevention of unwanted and high-risk pregnancies [2]. The Beijing world women conference in 1995 also re-enforced this message when it recognized the importance of "shared responsibility between men and women in all issues related to reproductive health".

Family planning programs should always be a concern for both the man and the woman. Historically though, most of the family planning programs have been a woman only affair. The programs targeted only women with very little or no attention to the role men play in respect to the overall family planning decisions [3].

Men in the developing world, Kenya included, are often the primary decision-makers about family size and use of family planning [4]. A considerable discordance between spouses on questions of family planning and desired family size has also been identified. In some developing countries, levels of communication on these topics are low. Inter-spousal communication is related to contraceptive decision-making and positively affects contraceptive uptake and continued use, whereas failure to communicate reproductive intentions limits couples' effective and sustained contraceptive use [5].

Male involvement is not only restricted to the uptake of male family planning methods but also includes the number of men who encourage and support their partners and their peers to use family planning. It also involves the influencing 
of policy environment to be more conducive to development of male related programs. Therefore, male involvement should be understood as all the organizational activities whose main aim is to increase the prevalence of contraceptive for either gender [6].

Failure to involve men in the family planning programs in a patriarchal society like Kenya has serious consequences even if women are motivated to practice contraception because of opposition from the spouse. This opposition accounted for $23 \%$ of the unmet family planning needs during the Kenya demographic and health survey [7]. This study was therefore aimed at establishing the demographic, social and health system factors associated with male involvement in family planning in West Pokot County.

\section{Materials and Methods}

\subsection{Study Design}

This was a cross sectional analytic study conducted during the month of July 2014. It used the quantitative approach to generate quantifiable data that could be generalized to the entire study population.

A structured interview questionnaire was used to collect data from the respondents. The structured questionnaire was designed to evaluate the population's demographics, social, and institutional factors in relation to male involvement in family planning. Trained study enumerators were engaged to collect data at the household level under the supervision of the principal investigator.

The location and the sub- location for the study were selected by random sampling. The three locations of Kapenguria Division were listed on pieces of paper, folded and placed in a container and Mnangei location was randomly picked. The same procedure was done for the four sub locations in Mnangei Location and Keringet sub location, which has six villages, was picked for the study. A total of 266 men were involved in the study. Probability Proportionate to sample was used to select the 266 respondents from six villages (clusters).

A house was the basic sampling unit in each village. Households were selected by standing in the middle of the village and spinning a pencil. The direction where the pencil pointed was taken and every household included in the study. In each selected household, one married man whose wife was aged 15 to 49 years and who has been a resident of the sub-location for a period not less than one year was interviewed after obtaining an informed consent. Only one male was interviewed per household. In case where there was more than one eligible man in the house, the one considered as the household head was interviewed. If there was only one eligible member of the household, but who at the time of the visit was away to a nearby place, say garden, the enumerator left a message and interviewed him later. If the only eligible person refused to consent to the study, he was excluded and the next household considered. And where the boundary of the village was reached without obtaining the required numbers of respondents, the enumerator turned to the direction of his right hand and continued with the same procedure until the required number was obtained.

\subsection{Study Population}

The study population included the married men living in Keringet sub location of West Pokot County.

\subsection{Inclusion Criteria}

All married men whose wives were still within the age bracket of 15-49 years (female reproductive age) during the period of study.

\subsection{Exclusion Criteria}

Any man who fitted into the above criteria but not physically present during the study period.

\subsection{Selection and Training of Enumerators}

Six male research enumerators were recruited from within the community. The Investigator conducted a two day training to orientate the enumerators on data collection and to standardize the whole process.

\subsection{Pre-testing of Research Instruments}

The research instruments were pre-tested once on 15 participants in a similar population before the actual data collection. The pre-test checked on the answerability, sequence, and the appropriateness of questions. It also timed the duration of each interview session. The experience from the pre-test informed the researcher on the necessary adjustments required in the tool.

\subsection{Ethical Considerations}

Ethical approval was obtained from research and ethics committee of the Great Lakes University of Kisumu upon approval of the research proposal. The major ethical issues which were adhered to during the process of study include; voluntary participation, obtaining informed consent from every participant before enrolment, ensuring privacy and confidentiality of the respondents. Institutional ethical, scientific honesty and competency were also considered. Consent to conduct the research was also obtained from the local provincial administration.

\subsection{Data Analysis}

Data was analyzed using Statistical Package for Social Studies (SPSS) version 17 and Microsoft Excel. The analyzed data was presented in tables, graphs and charts. Correlation and Chi-square tests were utilized to assess the relationships between selected variables. Regression 
analyses were also performed to show the strength of association between selected variables and male involvement in family planning either.

\section{Results}

\subsection{Level of Male Involvement in Family Planning}

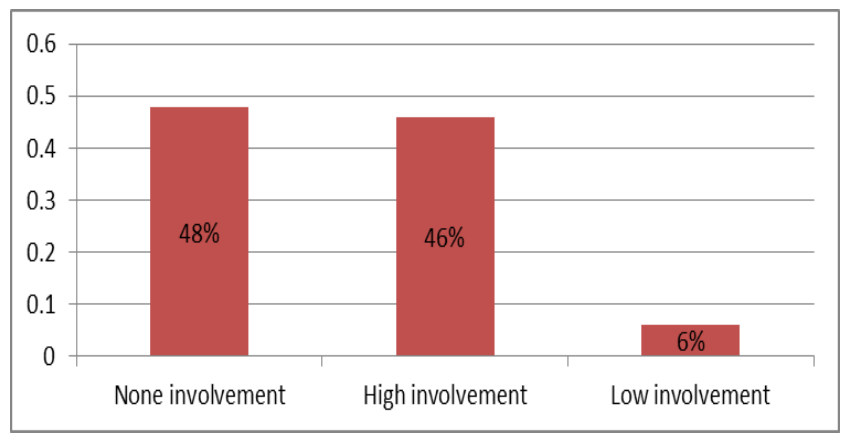

Figure 1. Level of Male involvement in family planning

The results of male involvement are summarized in Figure 1. In this study, high involvement was defined as 'Current use of FP by respondent', 'Discussion with wife on FP' and 'Current use of FP by wife'. Low Involvement was defined as 'just supporting the use of FP' and 'would encourage other men to use FP'. Overall, $47.74 \%$ of men in this study were not involved in whichever way in family planning while only $46.24 \%$ of the men were highly involved. Only $33 \%$ of the respondents reported that their wives were using a contraceptive method at the time of interview.

\subsection{Reasons for not Using Family Planning by the Respondents}

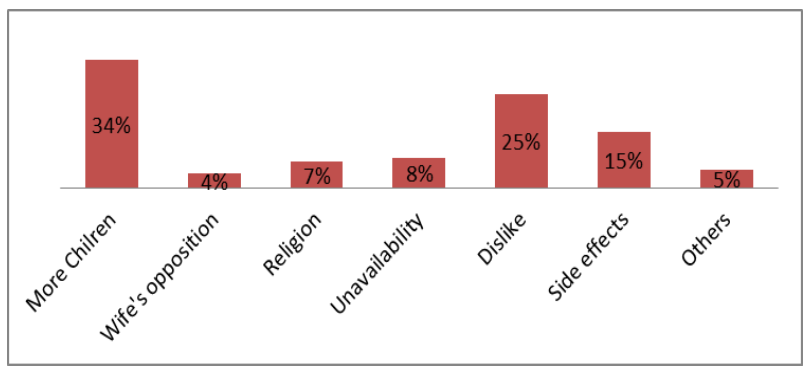

Figure 2. Distribution of respondents by reason for not involving family planning

The reasons of respondents for not involving family planning are summarized in Figure 2. When asked why they were not involved in family planning, majority of the respondents, $(33.8 \%)$ cited their desire to have more children, $25.2 \%$ said they did not like the family planning methods and another $13.5 \%$ cited the side effects.

\subsection{Characteristics of Demographic Factors}

Table 1. Distribution of respondents by demographic factors

\begin{tabular}{|c|c|c|}
\hline $\begin{array}{c}\text { Demographic Factors } \\
n=266\end{array}$ & Frequency & $\%$ Percentage \\
\hline \multicolumn{3}{|l|}{ Age group } \\
\hline $15-19$ & 1 & 0.4 \\
\hline $20-24$ & 18 & 6.8 \\
\hline $25-29$ & 72 & 27.1 \\
\hline $30-34$ & 65 & 24.4 \\
\hline $35-39$ & 52 & 19.5 \\
\hline $40-44$ & 30 & 11.3 \\
\hline $45-49$ & 18 & 6.8 \\
\hline $50-54$ & 8 & 3.0 \\
\hline $55-59$ & 2 & 0.8 \\
\hline \multicolumn{3}{|c|}{ Source of income for the respondent } \\
\hline Farming & 92 & 34.6 \\
\hline Business & 107 & 40.2 \\
\hline Salaried & 45 & 10.9 \\
\hline None & 14 & 5.3 \\
\hline Others & 18 & 3.0 \\
\hline \multicolumn{3}{|c|}{ Respondents educational level } \\
\hline None & 32 & 12 \\
\hline Primary incomplete & 53 & 19.9 \\
\hline Primary complete & 63 & 25.2 \\
\hline Secondary & 78 & 29.3 \\
\hline Tertiary & 36 & 13.5 \\
\hline
\end{tabular}

According to table 1 above, majority of the respondents, $27.1 \%$ were of the age group $25-29$ followed by $30-34$ at $24.4 \%$ and then $35-39$ at $19.5 \%$. The respondents' ages ranged from 19 to 57 years. Concerning the number of children, $39.1 \%$ of the respondents had between $1-3$ children, $36.1 \%$ had between $4-6$ children, while about $8 \%$ had 10 children and above. With regards to the main source of income, majority of the respondents, $40.2 \%$ were businessmen, $34.6 \%$ farmers, $16.9 \%$ had salaried job while $5.3 \%$ had reported that they did not have any source of income. When asked about their level of education, $31.9 \%$ of the respondents either had no formal education, or did not complete primary education, $29.3 \%$ had secondary education while only $13.5 \%$ were leaned up to tertiary level. 


\subsection{Characteristics of Social Factors}

Table 2. Distribution of Respondents by Social Factors

\begin{tabular}{|c|c|c|}
\hline Social Factors & $\begin{array}{c}\text { Frequency } \\
\mathrm{n}=266\end{array}$ & \% Percentage \\
\hline Group membership & & \\
\hline YES & 80 & $30.1 \%$ \\
\hline NO & 186 & $69.9 \%$ \\
\hline Religion of the respondent & & \\
\hline Catholic & 120 & $45.1 \%$ \\
\hline Anglican & 53 & $19.9 \%$ \\
\hline Muslim & 18 & $6.8 \%$ \\
\hline PCEA & 24 & $9.0 \%$ \\
\hline None & 29 & $10.9 \%$ \\
\hline Others & 22 & $8.3 \%$ \\
\hline Type of Marriage & & \\
\hline Married monogamous & 213 & $80.1 \%$ \\
\hline Married polygamous & 53 & $19.9 \%$ \\
\hline
\end{tabular}

The respondents' social factors are summarized in Table 2 above. With regards to social group membership, $69.9 \%$ of the respondents were not members of any social group while $30.1 \%$ belonged to a social group. Another social factor that was interrogated was religion and it was found that $45.1 \%$ of the respondents were Catholics, $19.9 \%$ Anglican, $6.8 \%$ Muslim, 9\% were members of PCEA while $8.3 \%$ belonged to other religions. Over $10 \%$ of the respondents were not affiliated to any religion. When asked about the type of marriage relationships, $80.1 \%$ of the respondents were in a monogamous marriage while $19.9 \%$ were polygamous.

\subsection{Characteristics of Institution Factors}

The institutional factors characteristics of the respondents are summarized in Table 3. Majority of the respondents, $81.2 \%$, knew where to get family planning services. Female health workers formed the majority of staff at the family planning service points followed by male health workers at
$75.1 \%$ and $18.2 \%$ respectively. When asked about the type of health facilities from where they get family planning services, majority of the respondents $(82.3 \%)$ cited government health facility, $10 \%$ said they buy from the local chemist and $6.8 \%$ from the private health facilities and a further $0.9 \%$ from community based distributers. Concerning the time taken to reach the service point, majority of the respondents $(45.5 \%)$ take $30 \mathrm{~min}-1$ hour, $33.6 \%$ take less than 30 minutes, and $19.1 \%$ take $1-3 \mathrm{hrs}$ while 1.80 take over $3 \mathrm{hrs}$. When asked about the ease of availability of family planning services in the community, majority of the respondents, $63.9 \%$ thought that family planning services for men were not easily available while $36.1 \%$ believed that the services were easily available in the community.

Table 3. Distribution of Respondents by Institution Factors

\begin{tabular}{|c|c|c|}
\hline Health Systems Factors & Frequency & $\%$ Percentage \\
\hline Type of facility & & \\
\hline Government owned health facility & 181 & $82.3 \%$ \\
\hline Private facility & 15 & $6.8 \%$ \\
\hline Buy from chemist & 32 & $10 \%$ \\
\hline From CBOs & 2 & $0.9 \%$ \\
\hline Time taken to the facility & & \\
\hline Less than 30mins & 74 & $33.6 \%$ \\
\hline 30 mins-1 hrs & 100 & $45.5 \%$ \\
\hline 1hr-3hrs & 42 & $19.1 \%$ \\
\hline Over 3hrs & 4 & $1.8 \%$ \\
\hline Ease of FP availability for men & & \\
\hline Yes & 95 & $36.1 \%$ \\
\hline No & 168 & $63.9 \%$ \\
\hline Providers of FP services & & \\
\hline Female health workers & 171 & $76 \%$ \\
\hline Male health workers & 41 & $18.2 \%$ \\
\hline Others & 13 & $5.8 \%$ \\
\hline
\end{tabular}




\subsection{Relationship between Demographic Factors and Male Involvement in Family Planning}

Table 4. Demographic factors and level of involvement

\begin{tabular}{|c|c|c|c|c|c|c|}
\hline \multirow{2}{*}{$\frac{\text { Demographic Factors }}{\text { Age group }}$} & \multicolumn{3}{|c|}{ Level of Involvement } & \multirow[t]{2}{*}{$\mathrm{X}^{2}$} & \multirow[t]{2}{*}{ df } & \multirow[t]{2}{*}{$\mathrm{p}$-value } \\
\hline & High & Low & None & & & \\
\hline $15-19$ & $0 \%$ & $0 \%$ & $100.0 \%$ & & & \\
\hline $20-24$ & $55.6 \%$ & $5.6 \%$ & $38.9 \%$ & & & \\
\hline $25-29$ & $51.4 \%$ & $5.6 \%$ & $43.1 \%$ & 38.106 & 16 & 0.001 \\
\hline $30-34$ & $52.3 \%$ & $7.7 \%$ & $40.0 \%$ & & & \\
\hline $35-39$ & $51.9 \%$ & $1.9 \%$ & $46.2 \%$ & & & \\
\hline $40-44$ & $26.7 \%$ & $3.3 \%$ & $70.0 \%$ & & & \\
\hline $45-49$ & $27.8 \%$ & $0 \%$ & $72.2 \%$ & & & \\
\hline $50-54$ & $25.0 \%$ & $37.5 \%$ & $37.5 \%$ & & & \\
\hline $55-59$ & $0 \%$ & $50.0 \%$ & 50.0 & & & \\
\hline \multicolumn{7}{|l|}{ Number of children } \\
\hline $1-3$ & $59.6 \%$ & $6.7 \%$ & $33.7 \%$ & 42.088 & 10 & 0.000 \\
\hline $4-6$ & $50.0 \%$ & $4.2 \%$ & $45.8 \%$ & & & \\
\hline $7-9$ & $30.2 \%$ & $2.3 \%$ & $67.4 \%$ & & & \\
\hline $10-12$ & $0 \%$ & $13.3 \%$ & $86.7 \%$ & & & \\
\hline $13-15$ & $0 \%$ & $16.7 \%$ & $83.3 \%$ & & & \\
\hline $16-18$ & $0 \%$ & $50.0 \%$ & $50.0 \%$ & & & \\
\hline \multicolumn{7}{|l|}{$\begin{array}{c}\text { Source of income for the } \\
\text { respondent }\end{array}$} \\
\hline Farming & $40.2 \%$ & $4.3 \%$ & $55.4 \%$ & & & \\
\hline Business & $45.8 \%$ & $6.5 \%$ & $47.7 \%$ & 15.037 & 8 & 0.058 \\
\hline Salaried & $60.0 \%$ & $4.4 \%$ & $35.6 \%$ & & & \\
\hline None & $28.6 \%$ & $21.4 \%$ & $50.0 \%$ & & & \\
\hline Others & $75.0 \%$ & $0 \%$ & $25.0 \%$ & & & \\
\hline \multicolumn{7}{|c|}{ Respondents educational level } \\
\hline None & $19.7 \%$ & $8.2 \%$ & $72.1 \%$ & 32.549 & 8 & $\begin{array}{c}0.000 \\
\mathbf{0 . 1 1 7} \\
\mathbf{( 0 . 0 3 0 - 0 . 4 5 4 )} \\
\end{array}$ \\
\hline Primary incomplete & $43.7 \%$ & $4.2 \%$ & $52.1 \%$ & & & \\
\hline Primary complete & $51.9 \%$ & $9.3 \%$ & $38.9 \%$ & & & \\
\hline Secondary & $62.9 \%$ & $4.8 \%$ & $32.3 \%$ & & & \\
\hline Tertiary & $72.2 \%$ & $0 \%$ & $27.8 \%$ & & & \\
\hline
\end{tabular}

Table 4 shows that respondents' age group and the number of children, which were significantly associated with level of involvement. In both cases, the level of male involvement in family planning decreased with increasing age and number of children. Education level of the respondent was also significantly associated with the level of involvement. Having no education made a man $89 \%$ less likely to be highly involved in family planning (OD 0.117 ; 95\% CI: 0.03-0.454). 


\subsection{Association between Social Factors and Male Involvement in Family Planning}

Table 5. Social factors and level of involvement

\begin{tabular}{|c|c|c|c|c|c|c|}
\hline Social Factors & \multicolumn{3}{|c|}{ Level of Involvement } & \multirow[t]{2}{*}{$X^{2}$} & \multirow[t]{2}{*}{$\mathrm{df}$} & \multirow[t]{2}{*}{ p-value } \\
\hline Group membership & High & Low & None & & & \\
\hline YES & $52.5 \%$ & $6.3 \%$ & $41.3 \%$ & 1.991 & 2 & 0.370 \\
\hline NO & $43.5 \%$ & $5.9 \%$ & $50.5 \%$ & & & \\
\hline \multicolumn{7}{|l|}{ Religion of the respondent } \\
\hline Catholic & $50.8 \%$ & $3.3 \%$ & $45.8 \%$ & 27.081 & 10 & 0.003 \\
\hline Anglican & $43.4 \%$ & $11.3 \%$ & $45.3 \%$ & & & \\
\hline Muslim & $38.9 \%$ & $22.2 \%$ & $38.9 \%$ & & & \\
\hline PCEA & $54.2 \%$ & $4.2 \%$ & $41.7 \%$ & & & \\
\hline None & $20.7 \%$ & $0 \%$ & $79.3 \%$ & & & \\
\hline Others & $59.1 \%$ & $4.5 \%$ & $36.4 \%$ & & & \\
\hline \multicolumn{7}{|l|}{ Type of Marriage } \\
\hline Married monogamous & $52.1 \%$ & $5.6 \%$ & $42.3 \%$ & 14.980 & 2 & $\begin{array}{l}0.001 \text { ( OD:3.803 } \\
\text { CI:1.873-7.719) }\end{array}$ \\
\hline Married polygamous & $22.6 \%$ & $7.5 \%$ & $69.8 \%$ & & & \\
\hline
\end{tabular}

Table 5 above shows that among the social factors, religion of the respondent $(\mathrm{p}=0.003)$ and type of marriage $(\mathrm{p}=0.001)$ were significantly associated with level of male involvement in family planning. Respondents who were not members of any religion were relatively more involved in family planning. However group membership $(p=0.370)$ was not significantly associated with level of male involvement. With regards to the type of marriage union, being in a monogamous marriage made a man 3.8 times more likely to be highly involved in family planning (OD: 3.803[1.873-7.719]).

\subsection{Association between Health System Factors and Level of Involvement}

Table 6. Relationship between Health system factors and Involvement

\begin{tabular}{|c|c|c|c|c|c|c|}
\hline \multirow{2}{*}{$\begin{array}{c}\text { Health systems factors } \\
\text { Type of facility }\end{array}$} & \multicolumn{3}{|c|}{ Level of Involvement } & \multirow[t]{2}{*}{$\mathrm{X}^{2}$} & \multirow[t]{2}{*}{$\mathrm{df}$} & \multirow[t]{2}{*}{$\begin{array}{l}\text { p-value (Odds } \\
\text { Ratio) }\end{array}$} \\
\hline & High & Low & None & & & \\
\hline Government health facility & $54.1 \%$ & $7.2 \%$ & $38.7 \%$ & 4.972 & 6 & 0.547 \\
\hline Private facility & $46.7 \%$ & $0 \%$ & $53.3 \%$ & & & \\
\hline Buy from chemist & $63.6 \%$ & $9.1 \%$ & $27.3 \%$ & & & \\
\hline From CBOs & $100.0 \%$ & $0 \%$ & $0 \%$ & & & \\
\hline \multicolumn{7}{|l|}{ Time taken to the facility } \\
\hline Less than $30 \mathrm{mins}$ & $55.4 \%$ & $2.7 \%$ & $41.9 \%$ & 6.325 & 6 & 0.388 \\
\hline 30mins-1 hr & $53.0 \%$ & $10.0 \%$ & $37.0 \%$ & & & \\
\hline $1 \mathrm{hr}-3 \mathrm{hrs}$ & $59.5 \%$ & $4.8 \%$ & $35.7 \%$ & & & \\
\hline Over 3 hrs & $50.0 \%$ & $25.0 \%$ & $25.0 \%$ & & & \\
\hline \multicolumn{7}{|l|}{ Ease of FP availability for men } \\
\hline Yes & $57.9 \%$ & $8.4 \%$ & $33.7 \%$ & 10.991 & 2 & $\begin{array}{c}0.004 \text { (2.325: } \\
1.359-3.978 \\
)\end{array}$ \\
\hline No & $40.5 \%$ & $4.8 \%$ & $54.8 \%$ & & & \\
\hline \multicolumn{7}{|l|}{ Providers of FP services } \\
\hline Female health workers & $53.3 \%$ & $7.7 \%$ & $39.1 \%$ & 14.558 & 8 & 0.068 \\
\hline Male health workers & $68.3 \%$ & $4.9 \%$ & $26.8 \%$ & & & \\
\hline Others & $23.1 \%$ & $0 \%$ & $76.9 \%$ & & & \\
\hline
\end{tabular}


Health systems factors and involvement levels are summarized in Table 6 . The Table 6 indicates that among the health system factors, only ease of family planning services availability for men was found to be significantly associated with level of involvement of the men in family planning $(p=0.004)$. The type of facility from where the respondent could get family planning services, $(p=0.547)$, time taken to reach the facility $(0.388)$ and the providers of family planning services $(p=0.068)$ were not significantly associated with level of involvement of men in family planning. Men who reported that family planning services were easily available in the community were 2.325 times more likely to be highly involved in family planning (OD 2.325, 95\% CI: 1.359-3.978).

\section{Discussion}

\subsection{Demographic Factors Associated with Male Involvement in Family Planning}

In this study, the majority of the respondents were in the age group of 25-29 years and the ages ranged from 19 to 57 years as indicated in Table 1. This age group is lower than those found in a study in Ghana by DeRose et al.[8], where the majority of the respondents fell in the age group of 35-39 years. This could be due to the Pokot culture that encourages men to marry early in life. Analysis demonstrated a significant relationship between the age of respondents and the level of involvement in family planning in west pokot, $(p=0.001)$. This finding however contradicted Green and $J$. Chens [9] on male involvement in reproductive health in Indonesia which did not find any association between age of the respondents and involvement in family planning and other reproductive health services.

With respect to the number of children, over $20 \%$ of the respondent had between seven and fourteen children. In the Pokot community, the more children one has, the highly he is placed in the community. In this study, there was a significant relationship between the number of children per respondent and the level of involvement in family planning, $(p=0.000)$. The number of men who were highly involved in family planning decreased with the increasing number of children such that the more children a man has, the more likely he will not be highly involved in family planning. These findings were in contrast with Agadjanian [10] study on gender, communication, and contraception in Urban Mozambique which found out those men with many children would be highly involved in family planning. Men as the decision makers in most marital and family matters may consider using family planning after they have already achieved their ideal number and sex composition of children.

Concerning the main source of income, majority of the respondents were either doing small businesses or subsistence farming as shown in Table 1. There was however no significant association between the source of income and male involvement in family planning in this region. This could be due to the fact that most family planning services are provided free of charge at the government facility. These findings were in contrast with the findings of a study in Mpigi District, Uganda[11], on male participation in family planning which found out that male who had regular salaried jobs were highly involved in family planning, and that stable source of income increased access and bargaining power for services including healthcare.

The level of education among the respondents was low with over $30 \%$ having no any form of formal education. The low education level in the county could be due to the nomadic culture where men move from one place to another looking for pasture for their livestock leading disruption of learning or dropping out of school all together. In this study, there was a great association between a man's level of education and his involvement in family planning, $\mathrm{p}=0.000$. A man with no education was 89 times less likely to be highly involved in family planning. This may be because education is likely to improve a man's knowledge on the importance of family planning, hence the positive association. These findings corresponded to a similar study in Ghana [12] which revealed that the level of men's education influences a couple's overall fertility preferences. A husband who is learned to a level beyond primary education influences his wife to limit childbearing. A man's preference for smaller family can lead women to desire fewer children which mean less responsibility and more spare time for both women and the man to be involved in social activities. A smaller family will allow the family members to raise their status through attaining higher education or by joining the labor force.

\subsection{Social factors Associated with Male Involvement in Family Planning}

This study explored membership to a social group, religion and types of marriage as the main social factors that could be associated with male involvement in family planning.

In this study, over $70 \%$ of the respondents were not members of any formal social groups. Membership to a social group in this study was not significantly associated with male involvement in family planning. This was not in line with a study by Montgomery [13] that found out that everybody belongs to formal or informal social networks that influence their behavior to some degree. Social networks include the extended family, friends, neighbors, political groups, church group, youth groups, and other formal and informal associations. Another study [14], also found out that for many men, informal communication is a primary source of family planning information.

Religion is another form of social networks that can influence a person's health seeking behavior. The majority of the respondents in this study were mainly Christians with Catholics dominating at $45 \%$. There was a significant association between religion and involvement in family, $\mathrm{p}=0.003$. Interestingly, respondents who did not subscribe to any religion were more likely to be involved in family planning than their counterparts were subscribed to different 
religion. However, further analysis did not show any association between different denominations and male involvement in family planning.

The type of marriage in this study was defined as either monogamous or polygamous. Majority of the respondents were in a monogamous marriage but still about $20 \%$ were in a polygamous relationship. There was a significant association and relationship between the type of marriage and the level of male involvement in family planning $(p=0.001)$. Further multivariate analysis showed that monogamous marriage made a man 3 times more likely to be highly involved in family planning (OD 3.803CI:1.873-7.719). Children in the Pokot community and in most African set up are viewed as a source of wealth and prestige, and the more children one has, the higher his place in the community. To achieve this, men will marry more than one wife so that they can sire many children hence the less involvement in family planning in the polygamous relationships.

\subsection{Institutional Factors Associated with Male Involvement in Family Planning}

Institutional factors have been found to influence men involvement in family planning. In the study, the institutional factors that were explored included; type of facility from where the family planning services can be obtained, the duration of time taken to reach the facility, the ease of availability of family planning for men and the providers of family planning services.

Concerning the type of facility from where the respondents got their services, majority of the respondents $(82.3 \%)$ get their family planning services at a government health facility $6.8 \%$ get from the private health facility as indicated in figure. This may be due to fact that the study are being in a rural set up, there are very few private facilities. As shown in Table 6 , the type of facility from where the family planning services were obtained did not have any significant association with the level of male involvement in this study $(\mathrm{p}=0.547)$.

With regards to the time taken to reach the service point, majority of the respondents, $45.5 \%$ reported that they take 30 min-1 hour. This could have been due to the fact that the West Pokot district hospital, the main government facility that servers most of the respondent is about five kilometers from the study area. There was no relationship between the time taken to reach the facility and the level of male involvement in family planning in this study $\mathrm{p}=0.388$.

Majority of the men i.e. $63 \%$ interviewed reported that family planning services for men were not easily available to the community. There was a significant relationship between ease of availability of family planning services and the level of male involvement in family planning in this study, $\mathrm{p}=0.004$. Men who found family planning services to be easily available in the community were 2.325 times more likely to be highly involved in family planning (OD 2.325 , 95\% CI: 1.359-3.978) as shown in Table 6. These findings were similar to Greene et al. [10] that the range of family planning methods available to men is limited, and this as a result inhibits men's capacity to involve in fertility regulation. A study by Heinemann et. al. [15] concluded that men would use a hormonal male contraceptive, delivered by injection and/or implant; this would be less intrusive method, likely that men will show more interest in using family planning. Unfortunately, the production of such a method for men does not seem to be possible in the near future.

Access to family planning services and the overall involvement in family planning services by men can also be influenced by the type of health workers offering the services. Female health workers formed the majority of staff at the family planning service points constituting over $75 \%$. The type of service providers was not associated with male involvement in family planning $(\mathrm{p}=0.068)$. Nzoka [16] in his study on men involvement and its implications on policy and program development in reproductive health concluded that the reality is that family planning services available for men are few and, besides, the facilities providing family planning services are also not enough, even the few available are not male user-friendly and are female dominated affecting male involvement.

\section{Conclusions and Recommendations}

\subsection{Conclusions}

The study concludes that the level of male involvement in family planning in the county is still low despite interventions both by the government and other nongovernmental organizations in trying to increase the prevalence of family planning. The demographic factors that were found to be significantly associated by male involvement in family planning in this study were age, number of children, and the educational level of the respondent. The social factors those were significantly associated with male involvement in family planning in this study included membership to a social group and religion of the respondent, while the religion of the respondent was not significantly associated with family planning. Knowledge factors in the study were significantly associated with the level of male involvement. Knowledge of a facility offering family planning services, general knowledge about family planning and knowledge of specific family planning methods available to both men and women all had significant association. On the other hand, only ease of availability of family planning services for men was significantly associated with male involvement. The type of health workers offering the services, distance to and type of health facility did not have any significant association with involvement in family planning in west Pokot County.

\subsection{Recommendations}

This study recommends that concerted efforts should be put in community sensitization and awareness campaigns 
aimed at increasing male involvement in family planning in this community. The various contraceptive options available for either and the benefits of planning families should be highlighted to the community at all cost. Stakeholders including community leaders, social workers, government and non-governmental agencies must come together to improve the prevalence of contraceptive uptake in this region.

Male involvement in family planning was found to increase with increasing level of education, hence the need for the community to invest in education of the boy child.

Formal and informal social grouping e.g. religions that provide information and promote male involvement in family planning should be encouraged.

Healthy public policies and reorientation of health services to make family planning services accessible and male friendly should advocated for.

Finally, research should be done to come up with more contraceptive options for men e.g. hormonal contraceptive methods.

\section{Acknowledgements}

I am deeply humbled by both financial and moral support I received from my dear wife, Jemima Wamboi, without which this work would not have been possible. I wish to thank Dr. Careena Otieno and Leila Gateri both of Great Lakes of Kisumu for their technical inputs. Special thanks to my colleagues at Kirinyaga University College for their patience and encouragement during the course of this study.

\section{REFERENCES}

[1] WHO. Addressing the challenges of women's health in Africa.The commission on women's health in Africareport.WHO Africa Office.2012.

[2] J.Levy. Reaching the Goals of Cairo.Male Involvement in Family Planning, online available

fromhttp://www.gi.unc.edu/research/carolina.papers/healt hpapers.htm. 2008.

[3] RHM. Men and Reproductive Health Overview. RHM archives, online available from http://www.rho.org/ html/menrh-links.html.2009.

[4] C. Nzioka. Research on men and its implications on policy and program development in reproductive health. In: Programming for Male Involvement in Reproductive Health. WHO regional advisors in reproductive health report, WHO/PAHO, Washington DC, September 5---7, 2001.
Geneva, Switzerland: World Health Organization; 2002:143----152. 2002.

[5] K. A.Oyediran, G. P. Ishola. \& B. J.Feyisetan. "Factor Affecting Ever-Married Men's Contraceptive Knowledge and Use in Nigeria", Journal of Biosocial Science, Vol. 34, pp.497-510, Cambridge University Press, United Kingdom. 2002.

[6] P. C. Green \& J Chens. HBC Male Involvement in Reproductive Health. CPD UNFPA. Paper 27, online available from http://www.cpd.org.bd/pub_attach/unfpa27.pd. 2003.

[7] KNBS \& ICF Macro. Kenya Demographic and Health Survey, 2008-09. Calverton, Maryland: Kenya National Bureau of Statistics and ICF Macro. 2010.

[8] L. F. DeRose, Ezeh A. C. "Men's Influence on the Onset and Progress of Fertility Decline in Ghana, 1988-1998", Population Studies, Vol.59, No.2, July, pp.197-210. 2005.

[9] P. C. Green \& J Chens. HBC Male Involvement in Reproductive Health. CPD UNFPAReport. Paper 27, online available from http://www.cpd.org.bd/pub_attach/unfpa27.pd. 2003.

[10] V. Agadjanian. “Men's Talk about Women's Matters: Gender, Communication, and Contraception in Urban Mozambique", Gender and Society, Vol.16, No.2, April, pp.194-215.2002.

[11] A. Kaida, W. Kipp, P. Hessel, J. Konde-Lule. "Male Participation in Family Planning: Results from A Qualitative Study in Mpigi District, Uganda", Journal of Biosocial Science, vol.37, pp.269-286, Cambridge University Press, United Kingdom.2005.

[12] L.F. DeRose, Ezeh, A.C. "Men's Influence on the Onset and Progress of Fertility Decline in Ghana, 1988-1998", Population Studies Journal, Vol.59, No.2, July, pp.197-210.2005.

[13] M. R. Montagomery and W. Chung. Social network and the diffusion of fertility control: The Korean case. Values and fertility change conference, Sion, Switzerland, Feb 16-19, 44p. (Unpublished). 2000 .

[14] N.Rutenberg\& S. C. Watkins. The buzz outside and clinics: Conversations and contraception in Nyanza Province, Kenya. Studies in Family Planning 28 (4): 290-307. 2002.

[15] Heinemann. Male Participation in family; A Review of Programme Approaches in the Africa Region. Male participation conference, Banjul the Gambia. 2005.

[16] C.Nzioka. Research on men and its implications on policy and program development in reproductive health. In: Programming for Male Involvement in Reproductive Health. Report of the Meeting of WHO Regional Advisors in Reproductive Health, WHO/PAHO, Washington DC, September 5---7, 2001. Geneva, Switzerland: World Health Organization; 2002:143----152.2002. 